\title{
Influence of temperature on the properties of non-air-entrained and air-entrained cement mortars modified with different plasticisers and superplasticisers types
}

\author{
Beata Łaźniewska-Piekarczyk ${ }^{1, *}$ \\ ${ }^{1}$ Sielsian University of Technology, Faculty of Civil Engineering, Department of Building Materials \\ and Process Engineering, Akademicka 5, 44-100 Gliwice, Poland.
}

\begin{abstract}
The paper presents the results of the research on the impact of low and high temperature on the air content and consistency of non-airentrained and air-entrained and plasticized or superplasticized mortars according to PN-EN 480-1, which were made with CEM I cement. In case of the mortar with CEM I, various types of plasticizers and superplasticizers as well as aeration admixtures differing in chemical base were used. The analysis of the results of the research indicates that the effect of temperature influences the consistency and air-content of the mortar depending on the result of the type of plasticizing and superplasticizing admixture.
\end{abstract}

\section{Introduction}

The most commonly used chemical additives in building practice are admixtures modifying rheological properties of concrete mix, plasticizing (plasticisers) and significantly plasticizing (superplasticizers). These additives are different because of the various action on concrete mix. Therefore, the proper selection of these admixtures plays an extremely important role in the concrete technology [2,3]. Admixture effectiveness, with respect to both fresh and hardened concrete, depends on variables related to the cement, aggregates, and admixtures themselves, and also depends on external factors such as air temperature. A very important issue related to the use of plasticizing admixtures, and especially superplasticizing admixtures in building practice, is the compatibility of another admixtures with cements and additives and influence of temperature on the effectiveness of their cooperation. In case of frost-resistant and hydrotechnical concretes, air-entraining admixtures are used in addition to plasticizing and superplasticizing admixtures. Air-entraining admixtures are surface-active substances consisting of a long hydrocarbon chain terminated with a hydrophilic group. Chemical bases of air-entraining admixtures are fatty acid salts, alkaline salts of wood resins and alkaline salts of sulphates and sulphonates of organic compounds. In the presence of the air-entraining admixture, evenly spaced air bubbles of 20 to $200 \mu \mathrm{m}$ are formed during the concrete mixing. The air bubbles created a break in the

\footnotetext{
*Corresponding author: beata.lazniewska@polsl.pl
} 
continuity of capillaries, because of which the capillarity of the water decreases and frost resistance of concrete increases. Research conducted by $[4,5]$ has shown that it is very important to use different plasticizing and air-entraining at the same time to be compatible with each other. That is because, the use of superplasticizing admixtures with air-entraining admixtures can affect the degree of aeration of concrete mix, and superplasticizers themselves, added in larger quantities, can aerate the mixture to a large extent [9]. The generalization and, more importantly, the prediction of the influence of temperature on the properties of mixtures on cementitious binders, especially modified with many simultaneous admixtures present in its volume, is therefore a difficult issue and requires experimental verification.

The aim of the studies analysed in the article is to evaluate the interaction of various superplasticizers, plasticizers and air-entraining admixtures at different temperatures, both reduced and elevated, due to the properties of-fresh mortar.

\section{Research methodology}

\subsection{Properties of materials and mortar compositions}

The tests were performed on reference mortar acc. to PN-EN 480-1:2014 - Admixtures for concrete, mortar and grout. Test methods. Reference concrete and reference mortar for testing. The mortar composition is shown in Table 1. Basic information on the properties of cement, air-entraining admixture, plasticizers and superplasticizers is presented in Table 2 and Table 3.

Table 1. Mortar composition

\begin{tabular}{|c|c|c|}
\hline & & Amount in grams \\
\hline \multicolumn{2}{|c|}{ Cement CEM I $42.5 \mathrm{R}$} & 450.0 \\
\hline Water & $\mathrm{w} / \mathrm{c}=0.50$ & 225.0 \\
\hline \multicolumn{2}{|c|}{ Standard sand } & 1350.0 \\
\hline
\end{tabular}

Table 2. Mechanical, physical and chemical properties of CEM I $42.5 \mathrm{R}$

\begin{tabular}{|c|c|c|c|}
\hline Properties of cement & Unit & Average value & Standard \\
\hline 2 Days Strength & \multirow{3}{*}{$\mathrm{MPa}$} & 28.0 & $\geq 20.0$ \\
\hline \multirow{2}{*}{28 Days Strength } & & \multirow{2}{*}{57.2} & $\geq 42.5$ \\
\hline & & & $\leq 62.5$ \\
\hline Start of binding & $\min$ & 170 & $\geq 60$ \\
\hline Volume stability acc. to Le Chatelier & $\mathrm{mm}$ & 0.4 & $\leq 10$ \\
\hline Specific surface & $\mathrm{cm}^{2} / \mathrm{g}$ & 3681 & no requirements \\
\hline Loss on calcination & $\%$ & 2.87 & $\leq 5.0$ \\
\hline Content of insoluble residue & $\%$ & 0.79 & $\leq 5.0$ \\
\hline Sulphate content (as $\mathrm{SO}_{3}$ ) & $\%$ & 2.50 & $\leq 4.0$ \\
\hline Chloride content $\mathrm{Cl}^{-}$ & $\%$ & 0.059 & $\leq 0.10$ \\
\hline $\mathrm{Na}_{2} \mathrm{Oeq}$. & - & 0.63 & no requirements \\
\hline
\end{tabular}

The choice of the type of superplasticizer from the generic group, especially from PCE and PCP groups, was made based on the preceding preliminary tests, during which superplasticizers were eliminated, which significantly increased the air content in nonaerated mortar. In turn, the dosage of plasticizing and superplasticizing admixtures was selected so that non-air entrained mortar at $20^{\circ} \mathrm{C}$ had a similar slump flow diameter of approximately $21 \mathrm{~cm}$. 
However, the amount of aeration admixtures in the air-entrained mortar was determined based on the air content test in aerated concrete acc. to PN-EN 480-1 in the range of 5-7\%. The results of this test, for the same amount of aeration admixture with respect to the cement mass, mortar of the same standard, is aerated in $10 \%$. The dosage of admixtures with respect to the cement mass is given in Table 3 .

Table 3. Characteristics of superplasticizing, plasticizing and air-entraining admixtures.

\begin{tabular}{|l|l|l|l|}
\hline \multicolumn{2}{|l|}{ Admixture type } & Main chemical base & Dosage of admixture \\
\hline Superplasticizer & PCE & Polycarboxylate ether & 0.220 \\
\hline Superplasticizer & PCP & Polycarboxylate & 0.220 \\
\hline Superplasticizer & N & Modified naphthalene & 0.110 \\
\hline Superplasticizer & A & Acrylate-polyethylene glycol & 0.220 \\
\hline Superplasticizer & F & Modified phosphonates & 0.220 \\
\hline Plasticizer & NSF & Naphthalene sulfonate & 0.440 \\
\hline Plasticizer & MSF & Sulfonated melamine formaldehyde & 0.440 \\
\hline Plasticizer & MLS & Maleated lignosulfonate & 0.440 \\
\hline Air-entraining & AEA & Synthetic surface-active compounds & 0.015 \\
\hline Reference mortar & - & - & - \\
\hline
\end{tabular}

\subsection{The scope and method of determining the properties of mortars}

Air-entrained mortars for three ranges of their temperatures, 10,20 and $30^{\circ} \mathrm{C}$ were subjected to consistency and air-content tests. The study of the air content in mortars was performed using the method acc. to PN- EN 1015-7:1999: Methods of test for mortar for masonry. Determination of air content of fresh mortar. The mortar consistency test was carried out in accordance with the standard PN-EN 1015-3:1999: Methods of test for mortar for masonry. Determination of consistence of fresh mortar (by flow table).

\section{Analysis of test results}

The influence of temperature on the consistency of non-air-entrained mortars was analysed in the publication of Ghafoori and Diawar [10], Schmidt [11], who found that above $20^{\circ} \mathrm{C}$, the flow of non-air-entrained mixes decreases with increasing temperature. The test results are consistent with those presented in Fig. 1. There are also different reports on the behaviour of cement mortar with PCE plasticizers at various temperatures [12].

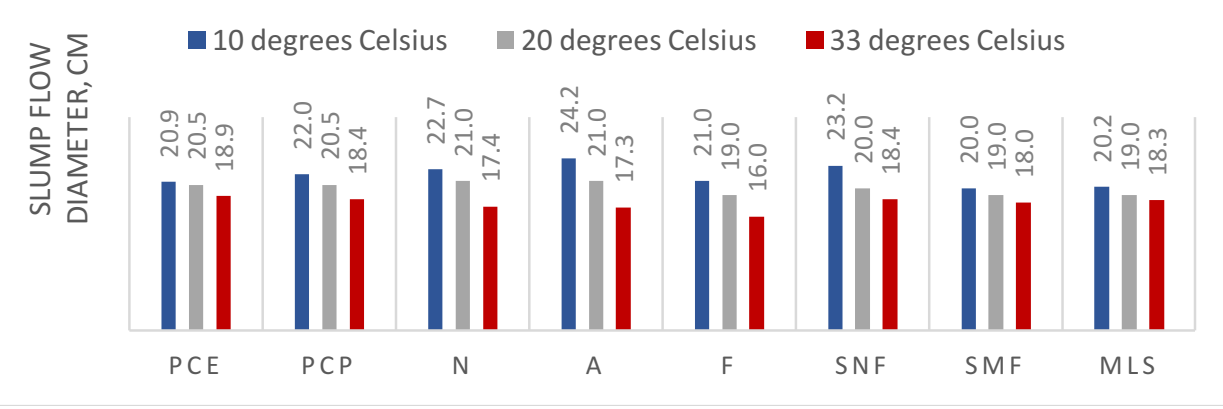

Fig. 1 Comparison of the influence of temperature on the flow diameter of non-air-entrained mortars with various types of superplasticizing and plasticizing admixtures. 
Results of the research [13] indicate that polycarboxylate-based superplasticizers should be used at a dosage close to the saturation in order to ensure adequate rheological behaviour at high temperature and prolonged mixing time, while melamine sulfonate- and naphthalene sulfonate-based superplasticizers should be used at dosages beyond the saturation level. This was the reason for the doubling of the amount of plasticizers due to superplasticizers in analysed studies (Table 3).

In order to know the effect of temperature influence on superplasticizers, first you need to know their behaviour at different temperatures, especially considering their spatial structure. Water-reducing admixtures stand out among the most used in concrete. They can be composed of various active ingredients, including lignosulfonate, naphthalene, and polycarboxylate. Such admixtures cause cement grains to disperse, and thus to have a plasticizing effect - through mechanisms of electrostatic repulsion and steric hindrance [1, 2]. Electrostatic repulsion, which explains how naphthalene and lignosulfonates work, is brought about by the adsorption of an (electrostatically negative) sulfonic group onto the surface of the cement grain, giving it a negative electrostatic charge. The predominance of negative charges on the surface of the grains leads to repulsion between particles, thus releasing the water that is held between them. In case of steric hindrance, the mechanism that describes how polycarboxylates work is that the particles adsorbed onto the cement grain have long side chains, which have greater repulsive capacity because they serve as physical impediments that prevent grains from bonding. Admixture effectiveness, depends on temperature. Test results [15] also show that the increase in the ambient temperature causes a decrease in mortar flow diameter, and the amount of reduction in the flow depends on the superplasticizer's contribution to the cement mass and type of the superplasticizer or the plasticizer. The publication [14] indicates that under the influence of temperature increase, or the presence of ions from salts easily dissociable in water, there are breaks in hydrogen bonds connecting the polyether chain with water (Fig. 2). As a result, the chain becomes entangled and the steric block gradually decreases until it disappears completely.

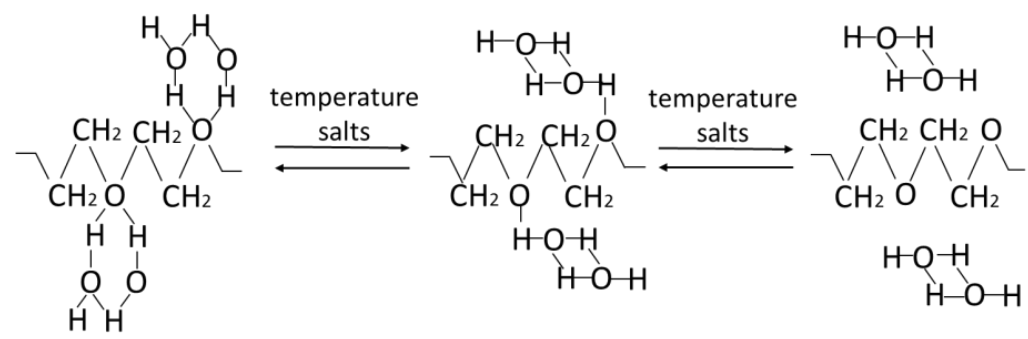

Fig. 2. Dehydration of polyether chains under the influence of temperature [14].

The results indicate that the increase in temperature leads to increase in saturation dosage; lignosulfonate had the most pronounced retarding effect, followed by polycarboxylate, and finally, naphthalene, and considering the weather conditions in the area where the study was carried, the final finding would be that the naphthalene-based admixture had the best performance [15]. Test results analysed in the paper showed that SNF mortar, among the other plasticizers, has the largest flow diameter at low temperature (Fig. 1), like cement paste with acrylates (A). In turn, the greatest reduction of flow at high temperature was demonstrated by the mortar with phosphonate (F). And the smallest mortar flow reduction at high temperatures corresponds to PCE and lignosulphonate (MLS) mortar. According to publication [12], there may even be the increase in the flow diameter of self-contaminated concrete from PCE at a higher temperature relative to the lower one.

In case of non-aerated mortars, the increase in temperature causes their reduction of the flow diameter (Fig. 1), and this in turn causes the increase in its aeration (Figs 3 and 4). 


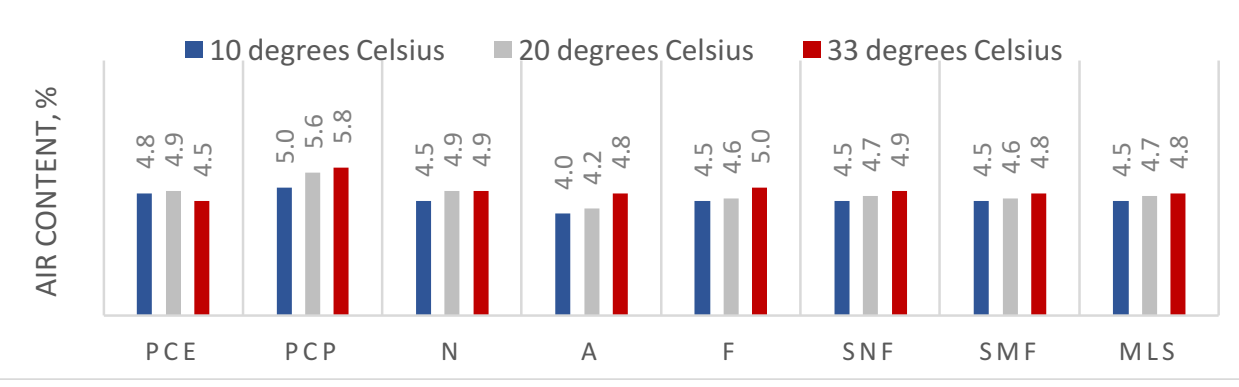

Fig. 3. Comparison of the influence of temperature on the air-content of non-air-entrained mortars with various types of superplasticizing and plasticizing admixtures.

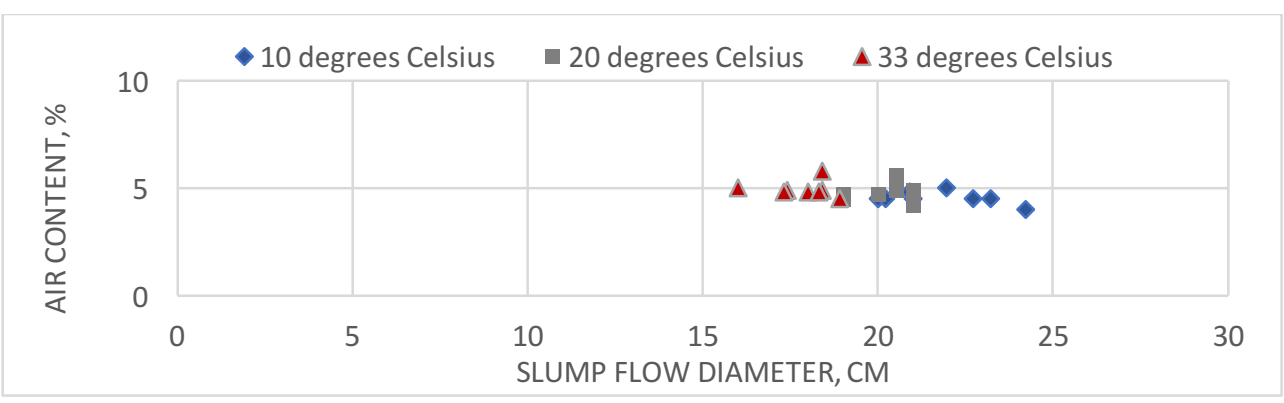

Fig. 4. Comparison of the relationship between the air-content in non-air-entrained mortars of different temperature and their flow diameter.

The influence of temperature on the consistency of air-entrained mortars, with various plasticizing or plasticizing admixtures, was not previously analysed in literature, in such scope as in the article. As shown by the results of the tests shown in Figs. 5 and 6 the impact of the superplasticizer and plasticizer type on the properties of air-entrained cement mortar at various temperatures is also important. The analysis of the test results indicates that the temperature rise always causes a reduction in the flow of the aerated and liquefied mortar, regardless of the type of admixture (Fig. 5). The type of plasticizing and superplasticizing admixture also strongly disturbs the relationship between the air content in mortar and its consistency in different temperatures (Fig. 7).

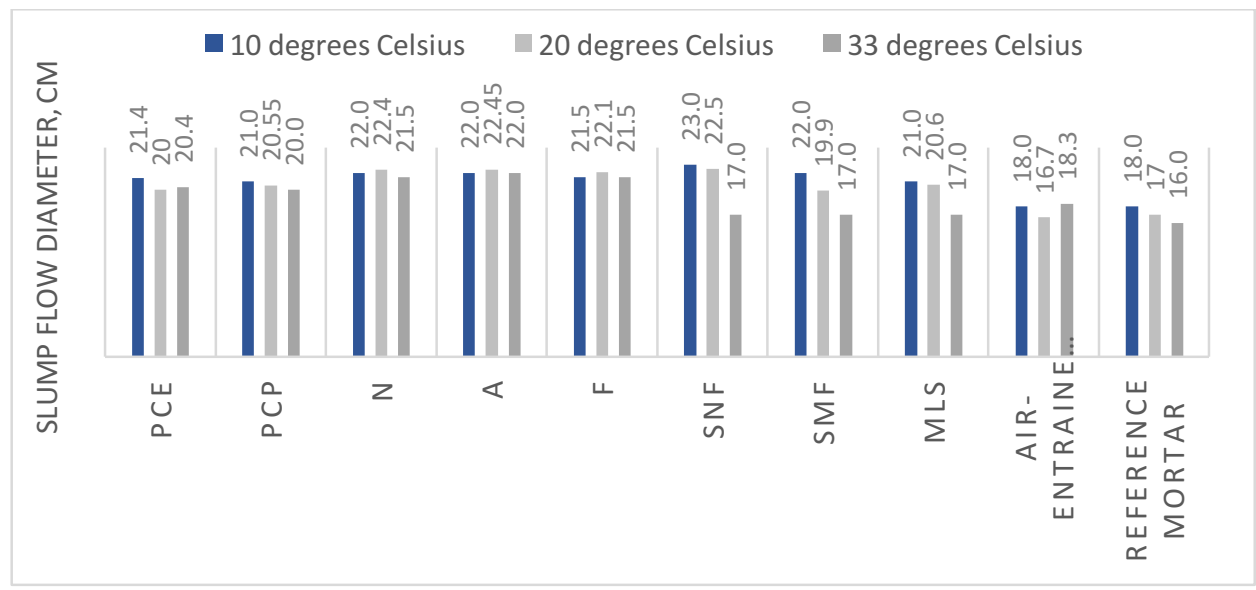

Fig. 5. Comparison of the influence of temperature on the flow diameter of air-entrained mortars with various types of superplasticizing and plasticizing admixtures. 


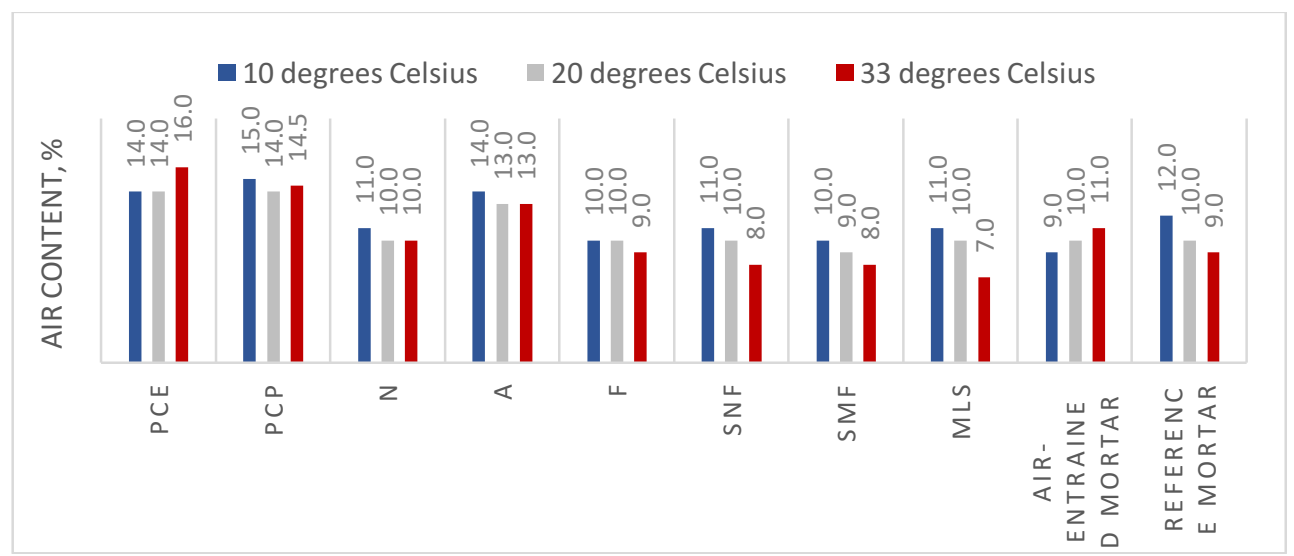

Fig. 6. Comparison of the influence of temperature on the air-content of air-entrained mortars with various types of superplasticizing and plasticizing admixtures.

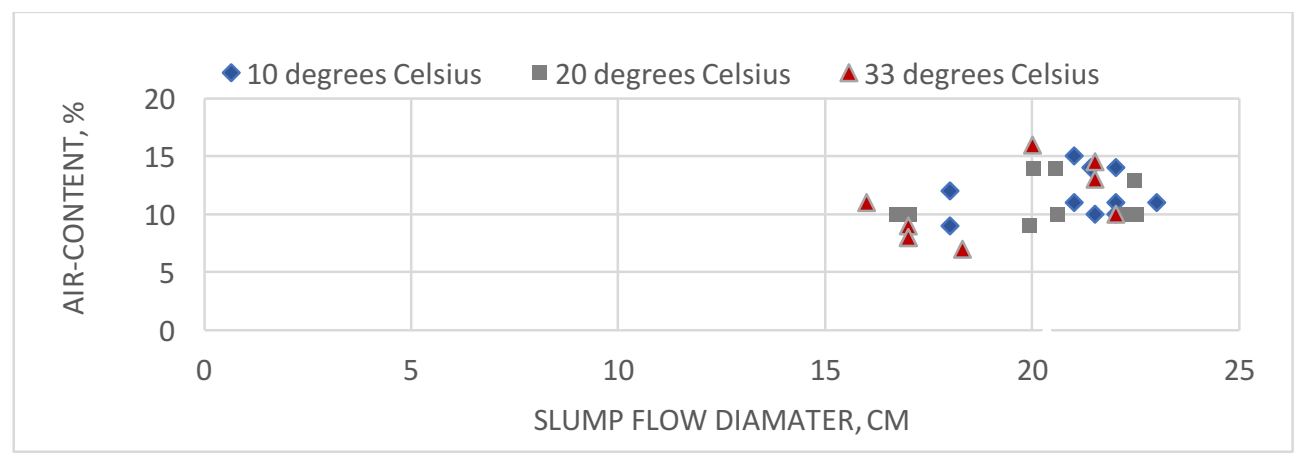

Fig. 7. Comparison of the relationship between the air-content in air-entrained mortars of different temperature and their flow diameter.

However, the air content and diameter of the flow of air-entrained mortars, with the increase of temperature, depending on the type of superplasticizing admixture, slightly increases or decreases, or does not change at all (Fig. 6). However, in case of superplasticizers, the reduction in the diameter and air-content of the mortar is less as the temperature increases than in case of plasticizers (Fig. 5). In addition, the size of the change in the flow and air-content of the mortar in the temperature range of 20-30 deg. C and 10-20 deg. $\mathrm{C}$ depends on the type of plasticizer and superplasticizer, which is consistent with the results of the studies [15].

Interestingly, in case of some PCE and PCP superplasticisers, the flow diameter and air content in the mortar can increase as the temperature increases. Similarly, in case of aerated mortar with lignosulphonate (MLS) the increase in temperature causes the increase in the air content, but no longer in the diameter of the flow. The reason for this is the strong influence of lignosulfonate plasticizer on the surface tension of water, as well as some PCE and PCP superplasticisers. The mechanisms of SP action include dispersion of cement particles by reduction in surface tension of mixing water and a decrease in frictional resistance because of the line-up of linear polymers along the concrete flow direction and lubrication properties produced by low molecular weight polymers [8]. The presence of functional groups (oxygen in form of etheric group (-O-), hydroxyl group (-OH) and carboxyl group) produce water surface tension decrease, producing flocculation of associated molecules and increase in moisture of not only grains of cement but also the whole mineral framework (Fig. 8). 


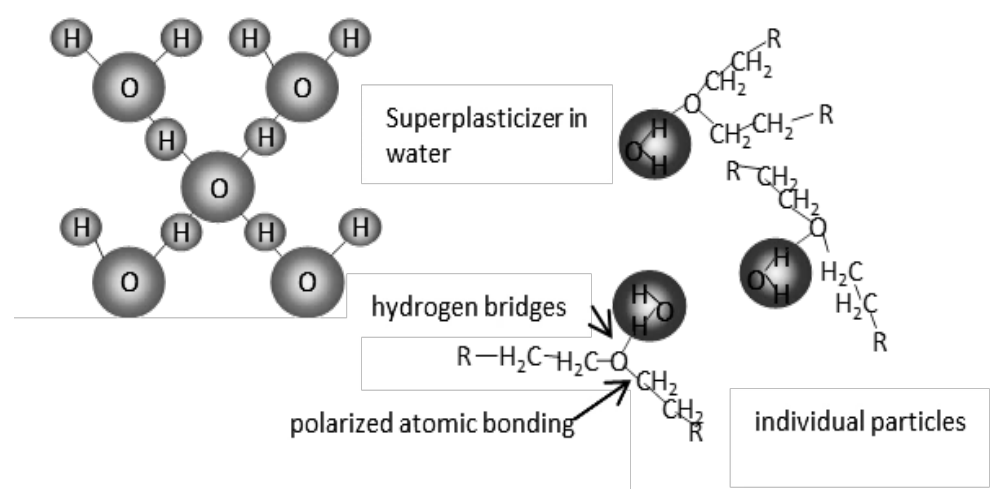

Fig. 8. Water conglomerates deflocculating under the influence of superplasticizer as the effect of surface tension diminution [16].

In case of high temperature of mortar, PCE and MLS admixtures reduced the flow diameters of the non-aerated mortar the least and caused the increase in the air-content of aerated mortar in case of PCE. The surface tension of aqueous solutions of some PCP and PCE superplasticizers is very low, almost like the admixtures. What's more, when such a superplasticizer is added to the air-entrained mortar, the surface tension of water decreases even more [17], and the increase of water temperature causes an even greater reduction of this value. The degree of reduction in surface tension corresponds to the air-entraining admixture [17]. Hence, the effect of increasing the flow of air-entrained mortars containing PCE and PCP and with lignosulfonate as the temperature increases. The surface tension, due to intermolecular interactions, is highly dependent on temperature. The dependence of the surface tension of the liquid on temperature is described by Eötvös (1886) equation [0]:

$$
\sigma\left(\frac{M}{d}\right)^{\frac{2}{3}}=K\left(T_{k}-T-\delta\right)
$$

where:

$\sigma$ - surface tension of the solution,

$\mathrm{M}$ - is the molar mass,

$\mathrm{D}$ - density of liquid (hence $\mathrm{M} / \mathrm{d}$ - is a volume of one mole),

$\mathrm{T}_{\mathrm{k}}$ - critical temperature,

$\delta$ - is a correction of about 6 deg (it turns out that the disappearance of surface tension occurs at a temperature slightly lower than $T_{k}$ ).

\section{Conclusions}

The effect of the temperature influence on the behaviour of air-entrained mortar, modified with superplasticizing or plasticizing admixtures, is variously directed, depending on the type of admixture and associated mechanism of the influence of admixture on cement paste. In the analysed area of the test results, it is concluded that:

- Mortar with SNF, among other investigated plasticizers SMF and MLS, has the largest flow diameter at low temperature, like cement paste with acrylates. In turn, the greatest reduction of flow at high temperature was demonstrated by the mortar with phosphonate. And the smallest mortar flow reduction at high temperatures corresponds to PCE and lignosulphonate mortar.

- The increase in temperature of the mortar slightly increases the flow diameter of the airentrained mortar, i.e. for some superplasticisers, i.e. highly reducing the surface tension 
of water, or reducing the mortar flow diameter, for other superplasticisers and all plasticizers.

- The increase in temperature of air-entrained and liquefied mortar causes various changes in its air-content: no change, or slightly increased air-content of the mortar (in case of superplasticizers with a greater impact on surface tension of water), and finally lowering (in case of other superplasticisers and all plasticizers, except for lignosulphonate where the air content increases).

\section{References}

1. P.C. Aitcin, Cement Wapno Beton 5 (2006)

2. L. Kucharska, Cement Wapno Beton 2 (2000)

3. W. Kurdowski, Cement Wapno Beton 5, 296-305 (2010)

4. S. Hanehara, K. Yamada, Cem. Concr. Res 29 (1999)

5. S. Erdogdu, Cement Wapno Beton 30 (2000)

9. B. Łaźniewska-Piekarczyk, Cement Wapno Beton 3, 133-145 (2009)

10. N. Ghafori, H. Diawara, Constr. Build. Mater. 24, 946-955 (2010)

11. W. Schmidt, Design concepts for the robustness improvement of self-compacting concrete - Effects of admixtures and mixture components on the rheology and early hydration at varying temperatures (Eindhoven: Technische Universiteit Eindhoven, 2014).

12. G. Cygan, J. Gołaszewski, M. Drewniok, The effect of temperature on the properties the self-compacting concrete, ACE LXII(3), 25-32 (2016)

13. S. Al Martini, Ph.D., M. Nehdi, JMCE 21(8) (2009)

14. S. Grzeszczyk, M. Sudoł, Cement Wapno Beton 6, pp. 325-331 (2003).

15. W.R.L. Silva, L.R. Prudêncio Jr., A.L. Oliveira, G. Damo, E. Tochetto, ACE 2010, 10 (2010)

16. T. Rudnicki, Autostrady 4, 22-25 (2004)

17. J. Szwabowski, B. Łaźniewska-Piekarczyk, Cement Wapno Beton 4, 205-215 (2008)

18. K. Pigoń, Z. Róziewicz, Physical chemistry (PWN, Warszawa, 6, 2018) 